\title{
Modified Polysulfone Membranes II. Pervaporation of Aqueous Ethanol Solution through Modified Polysulfone Membranes Bearing Various Hydroxyl Groups
}

\author{
Masakazu Yoshikawa, ${ }^{\dagger}$ Hirohisa Hara, Masataka TANigaki, \\ Michael Guiver, ${ }^{*}$ and Takeshi MatsunRA ${ }^{*+\dagger}$ \\ Department of Chemical Engineering, Faculty of Engineering, \\ Kyoto University, Kyoto 606, Japan \\ * Institute for Environmental Chemistry, National Research Council Canada, \\ Ottawa, Ontario, KIA 0R6, Canada
}

(Received February 25, 1992)

\begin{abstract}
Modified Udel P-3500 membranes bearing various kinds of hydroxyl moieties showed permselectivity towards water in the separation of aqueous ethanol solutions. Pervaporation phenomena were highly dependent on the environment surrounding the hydroxyl group.

KEY WORDS Pervaporation / Membranes / Permselectivity / Polysulfone / Polymer Modification /
\end{abstract}

Synthetic membranes, which are capable of energy efficient separations with high selectivity, have become a focus of our research activities. Novel membrane materials can be developed by several methods: polymerization of monomers by various polymerization methods, blending multi component polymers to form polymer alloys, or polymer modification. Among these, modification of existing polymers or polymeric membranes, especially those available commercially, is one promising route towards new membrane materials. In this paper, we have focused our attention on modification of polysulfone, ${ }^{1-7}$ which is an excellent polymer for membrane materials.

Polysulfone is a high performance thermoplastic well known for its mechanical strength and film forming quality. Polysulfones in which a hydrophilic moiety is introduced onto the polymer chain might render the polymer useful for water permselective pervaporation membranes. Several chemical methods to modify polysulfone have been reported. ${ }^{1-19}$ However, we know of only a few examples of polysulfone modification for pervaporation membranes. ${ }^{12,13}$

This work is one of the series of our studies on specialty polymeric membranes. ${ }^{20-24}$ In particular, we have investigated the pervaporation performance of modified polysulfone membranes bearing various kinds of hydroxyl moieties. We have also studied the effect of the substituent environment surrounding the hydroxyl group on pervaporation phenomena.

\section{EXPERIMENTAL}

\section{Materials}

Udel P-3500 polysulfone was obtained from Amoco Performance Products. Modification of

${ }^{\dagger}$ Present address: Department of Polymer Science and Engineering, Kyoto Institute of Technology, Matsugasaki, Kyoto 606, Japan

${ }^{\dagger \dagger}$ Present address: Industrial Membrane Research Institute, Department of Chemical Engineering, University of Ottawa, 161 Louis Pasteur, Ottawa, Ontario KIN 6N5, Canada. 


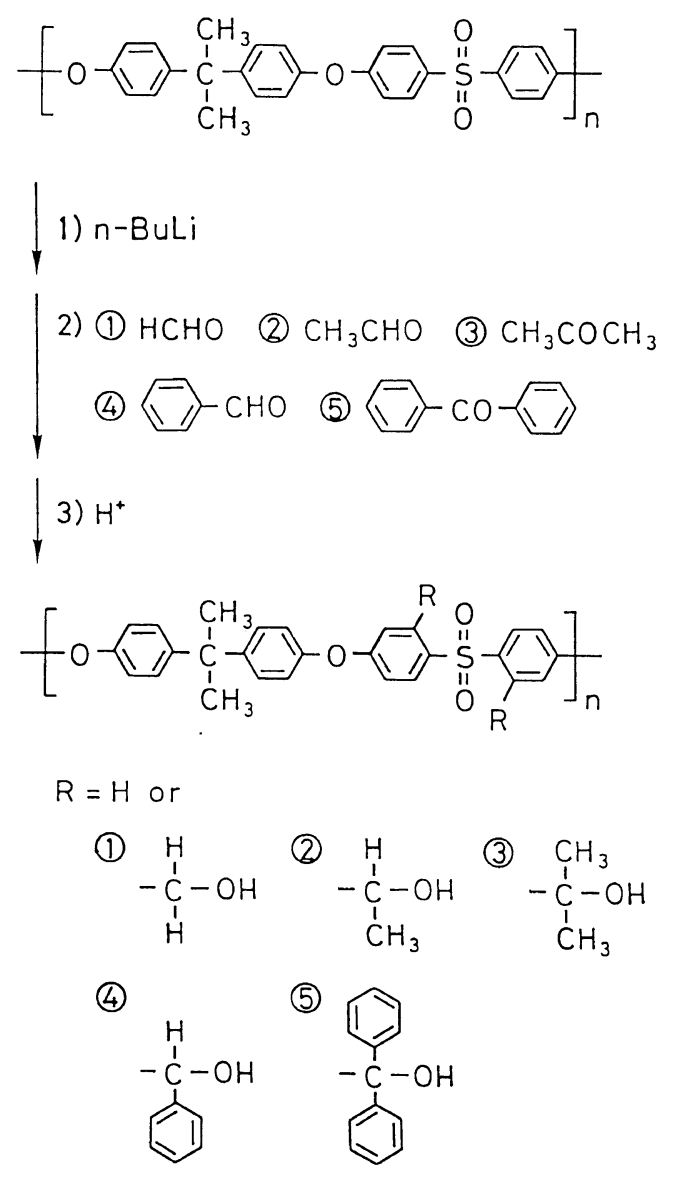

Scheme 1.

polysulfone by the introduction of hydroxyl moiety onto the polymer consists of three steps shown in the scheme as reported previously. ${ }^{25}$ 1) Lithiation with 1-butyllithium. 2) Reaction with carbonyl compounds, such as formaldehyde (starting material for 1), acetaldehyde (that for 2), acetone (that for 3), benzaldehyde (that for 4), and benzophenone (that for 5). 3) Protonation. Degrees of substitution for these modified polysulfones were as follows: 0.27 for 1, 0.36 for 2, 0.34 for 3, 0.42 for 4 , and 0.46 for 5 . Ethanol was purified in the usual manner. ${ }^{26}$ Deionized water was used.

\section{Preparation of Membranes}

All membranes were prepared by casting polymer solutions $\left(50 \mathrm{~g} \mathrm{dm}^{-3}\right)$ from chloroform. Solutions were cast onto glass plates with an applicator (casting thickness $254 \mu \mathrm{m}$ ), and the solvent was allowed to evaporate at ambient temperature overnight. The resulting membranes were dried at $45^{\circ} \mathrm{C}$ for $8 \mathrm{~h}$ and their thickness was from $9-15 \mu \mathrm{m}$.

\section{Pervaporation}

Pervaporation of water/ethanol mixtures was carried out by the method described previously. ${ }^{20}$ The membrane area in contact with liquid was $10.5 \mathrm{~cm}^{2}$. The downstream pressure was maintained at $400 \mathrm{~Pa}(3.0 \mathrm{mmHg})$.

The permeation rate was determined by weighing the permeate sample collected in a cold trap over a set period. The separation factor $\alpha$ was calculated by determining the composition of the feed liquid mixtures and permeates. The composition analysis was carried out using a Shimadzu GC-8A gas chromatograph with a 3.1 meter column packed with poly(ethylene glycol) 6000 on Shimalite TPA.

$$
\alpha=\left(Y_{\text {water }} / Y_{\text {alcohol }}\right) /\left(X_{\text {water }} / X_{\text {alcohol }}\right)
$$

where $Y_{i}$ is the weight fraction of component $i$ in the permeate and $X_{i}$ that in the feed.

\section{RESULTS AND DISCUSSION}

Figure 1 shows results of the pervaporation experiments, where the weight fraction of water in permeate is plotted as a function of water fraction in feed. Figure 2 gives the separation factor $(\alpha)$ and the total flux values plotted versus the weight fraction of water in feed. All the hydroxyl membranes were preferentially permeable to water. Solid lines in Figures 1 and 2 are calculated lines according to eq 2, 3, and 4 , and using the values for pervaporation parameters summarized in Table I, which are precisely described next.

In order to study the permeation mechanism of water and ethanol through these membranes, the observed total fluxes were separated 
Modified Polysulfone Membranes
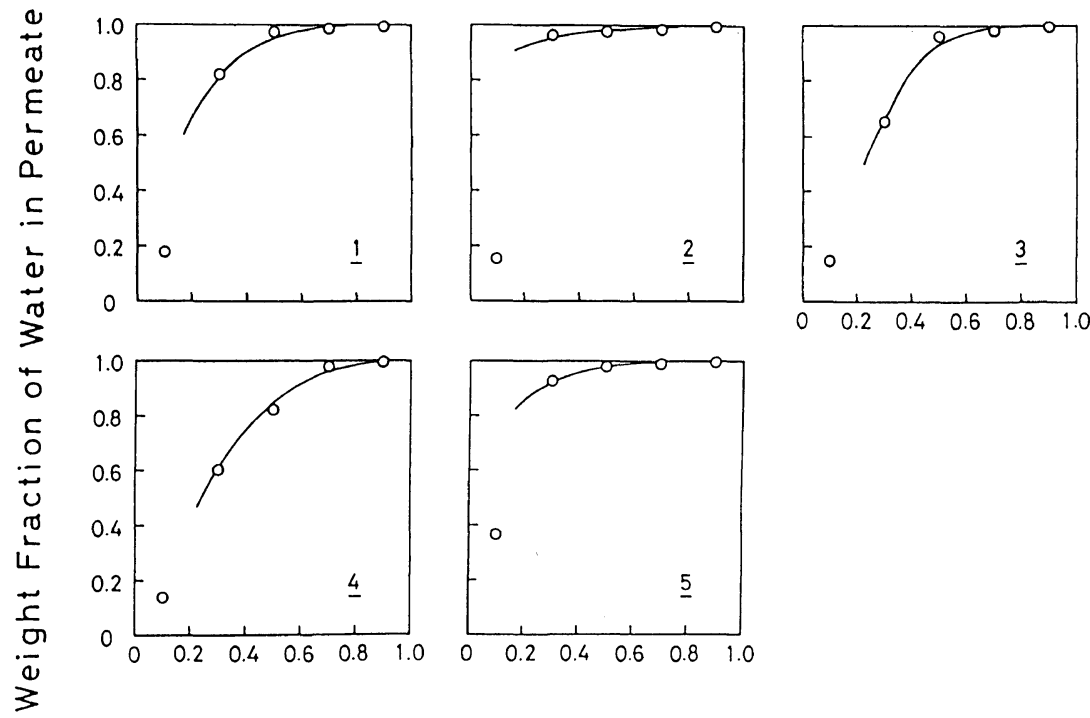

Weight Fraction of Water in Feed

Figure 1. Effect of feed composition on the weight fraction of water in the permeate. (Downstream pressure, $400 \mathrm{~Pa}(3.0 \mathrm{mmHg})$; operating temp, $25^{\circ} \mathrm{C}$; - , calculated, according to eq 2 and 3 , and using the numerical values given in Table I.)
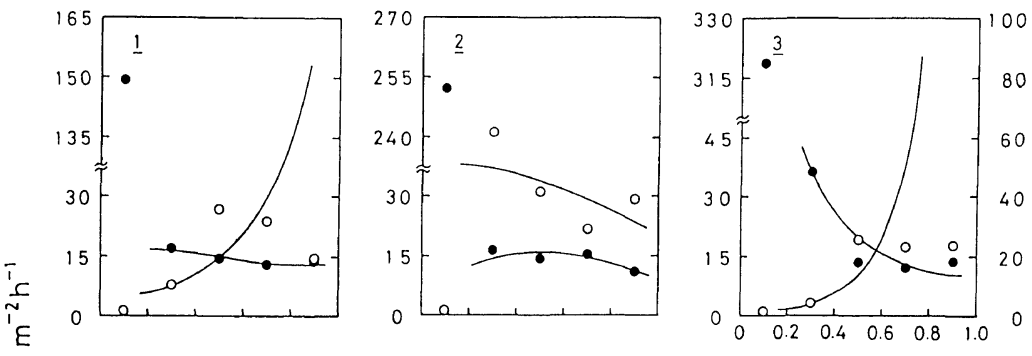

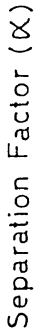
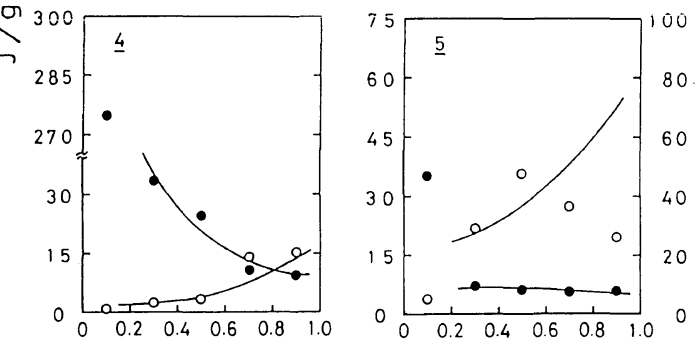

Weight Fraction of Water in Feed

Figure 2. Effect of feed composition on total flux and separation factor $(\alpha)$ in water/ethanol pervaporation. (Downstream pressure, $400 \mathrm{~Pa}\left(3.0 \mathrm{mmHg}\right.$ ); operating temp, $25^{\circ} \mathrm{C}$; 9 , flux; $\bigcirc$, separation factor $(\alpha)$; - , calculated, according to eq 2,3 , and 4 , and using the numerical values given in Table I.)

into their respective water and ethanol fluxes, as previously reported. ${ }^{20-24}$ Water flux versus feed water concentration, and ethanol flux versus feed ethanol concentration are plotted in Figure 3 for membrane 4 as an example. The ethanol curve shows an exponential profile. 
M. Yoshikawa et al.

Table I. Parameters for membranes ${ }^{\mathrm{a}}$

\begin{tabular}{|c|c|c|c|c|c|c|}
\hline \multirow{2}{*}{$\begin{array}{l}\text { Polymer } \\
\text { membrane }\end{array}$} & $10^{6} l$ & $10^{12} P_{0, \mathrm{E}}$ & $10^{12} P_{0, \mathrm{w}}$ & $10^{4} B_{\mathrm{EE}}$ & $10^{4} B_{\mathrm{WE}}$ & $10^{4} B_{\mathrm{ww}}$ \\
\hline & $\mathrm{m}$ & $\mathrm{m}^{2} \mathrm{~h}^{-1}$ & $\mathrm{~m}^{2} \mathrm{~h}^{-1}$ & $\mathrm{~m}^{3} \mathrm{~mol}^{-1}$ & $\mathrm{~m}^{3} \mathrm{~mol}^{-1}$ & $\mathrm{~m}^{3} \mathrm{~mol}^{-1}$ \\
\hline 1 & 9 & 0.90 & 2.8 & 4.3 & 5.0 & 1.0 \\
\hline 2 & 15 & 5.1 & 66 & 1.5 & 3.8 & 0.24 \\
\hline 3 & 10 & 0.20 & 0.086 & 7.0 & 8.5 & 1.7 \\
\hline 4 & 9 & 3.0 & 4.3 & 4.6 & 5.0 & 0.80 \\
\hline 5 & 9 & 0.54 & 4.1 & 3.1 & 4.5 & 0.68 \\
\hline
\end{tabular}

a Downstream pressure, $400 \mathrm{~Pa}(3.0 \mathrm{mmHg})$; operating temp, $25^{\circ} \mathrm{C}$.
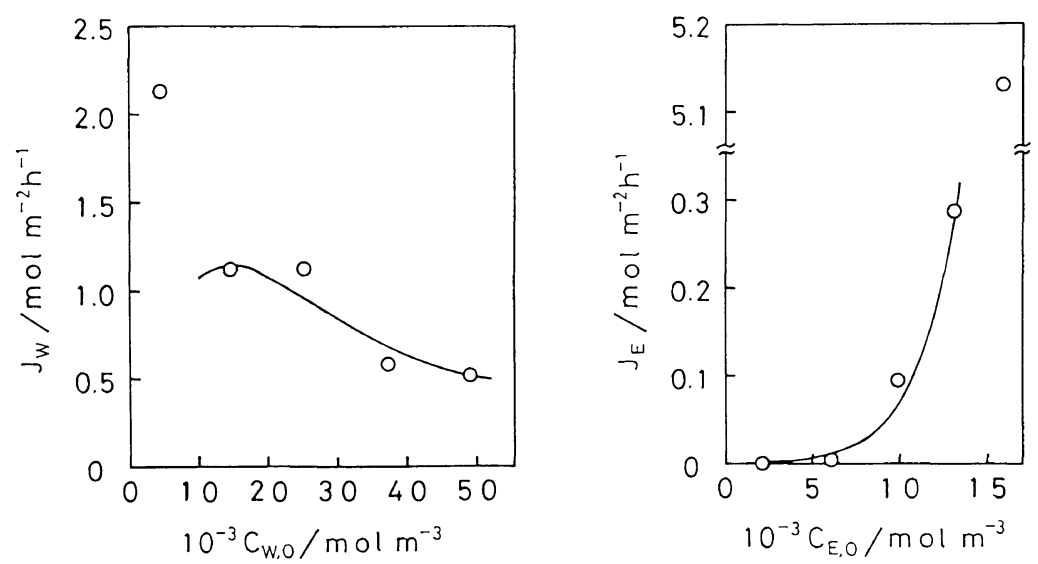

Figure 3. Effect of feed composition on fluxes of solution components through the membrane 4. (Downstream pressure, $400 \mathrm{~Pa}(3.0 \mathrm{mmHg})$; operating temp, $25^{\circ} \mathrm{C}$; -, calculated, according to eq 2 and 3 , and using the numerical values given in Table I.)

On the other hand, water flux dependence on its feed concentration appears more complicated. Profiles similar to Figure 3 were obtained for other membranes.

A similar profile was also obtained for modified polysulfone membranes having methyl ester moiety. ${ }^{24}$ In the latter case, both fluxes and separation factor $(\alpha)$ can be represented by the following equations. ${ }^{24}$

$J_{\mathrm{E}}=\left(P_{0, \mathrm{E}} / B_{\mathrm{EE}} l\right)\left\{\exp \left(B_{\mathrm{EE}} C_{\mathrm{E}, 0}\right)-1\right\}$

$J_{\mathrm{w}}=\frac{P_{0, \mathrm{w}}}{l} \frac{B_{\mathrm{EE}}-B_{\mathrm{WE}}}{B_{\mathrm{wW}} B_{\mathrm{EE}}}$

$$
\times \frac{\left\{\exp \left(B_{\mathrm{EE}} C_{\mathrm{E}, 0}\right)-1\right\}\left\{\exp \left(B_{\mathrm{WW}} C_{\mathrm{W}, 0}\right)-1\right\}}{\exp \left\{\left(B_{\mathrm{EE}}-B_{\mathrm{WE}}\right) C_{\mathrm{E}, 0}\right\}-1}
$$

$$
\begin{aligned}
\alpha= & \frac{J_{\mathrm{W}} / J_{\mathrm{E}}}{C_{\mathrm{W}, 0} / C_{\mathrm{E}, 0}}=\frac{P_{0, \mathrm{~W}}}{P_{0, \mathrm{E}}} \frac{B_{\mathrm{EE}}-B_{\mathrm{WE}}}{B_{\mathrm{WW}}} \\
& \times \frac{\left\{\exp \left(B_{\mathrm{WW}}-C_{\mathrm{W}, 0}\right)-1\right\} C_{\mathrm{E}, 0}}{\left[\exp \left\{\left(B_{\mathrm{EE}}-B_{\mathrm{WE}}\right) C_{\mathrm{E}, 0}\right\}-1\right] C_{\mathrm{W}, 0}}
\end{aligned}
$$

The same equations were found to be applicable for membranes with hydroxyl groups. $B_{\mathrm{EE}}$ and $P_{0, \mathrm{E}}$ were determined first by using ethanol flux-ethanol feed concentration relation and then $P_{0, \mathrm{w}}, B_{\mathrm{wE}}$, and $B_{\mathrm{ww}}$ were determined to fit the observed data. The five of parameters found in the above flux equations, determined to fit Figure 3, are summarized in Table I. Numerical values are also summarized in Table I for each membrane. Lines illustrated in Figures 1, 2, and 3 represent 


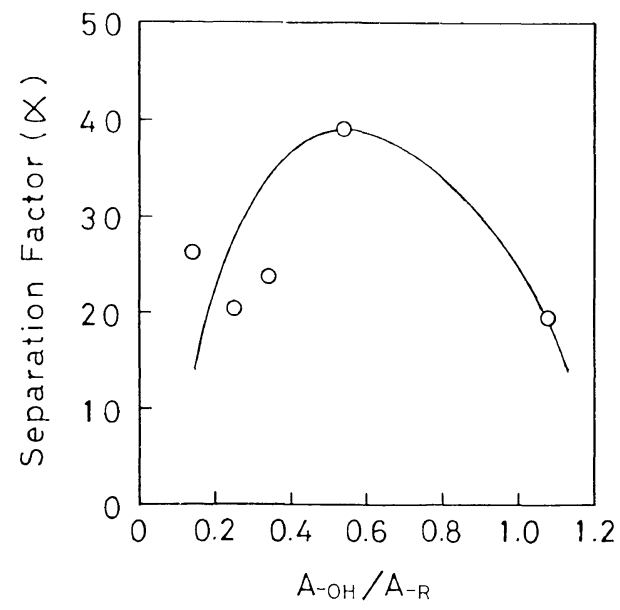

Figure 4. Relationship between separation factor $(\alpha)$ and surface area ratio.

\begin{tabular}{ccc}
\hline $\begin{array}{c}\text { Polymer } \\
\text { membrane }\end{array}$ & $A_{-\mathrm{OH}} / R_{-\mathrm{R}}$ & $\alpha^{*}$ \\
\hline $\mathbf{1}$ & 1.08 & 19.6 \\
$\mathbf{2}$ & 0.54 & 39.1 \\
$\mathbf{3}$ & 0.34 & 23.8 \\
$\mathbf{4}$ & 0.25 & 20.5 \\
$\mathbf{5}$ & 0.14 & 26.3 \\
\hline
\end{tabular}

a Downstream pressure, $400 \mathrm{~Pa}(3.0 \mathrm{mmHg})$; operating temp, $25^{\circ} \mathrm{C}$; feed water weight fraction of $c a .0 .9$.

the calculated values using the above numerical parameters in eq 2, 3, and 4 . Theoretical lines for the weight fraction of water in the permeate (Figure 1) and the total flux (Figure 2), agreed well with the experimental values above feed water weight fraction of 0.1 . On the other hand, theoretical lines for separation factor in Figure 2 , which is thought to be very sensitive to small errors in calculated flux values, did not agree well with the observed results. It was observed that the hydroxyl modified polysulfone membranes under study had a tendency to be swollen by the permeants, especially by ethanol. Quantitative evaluation of membrane swelling by the immersion technique failed because of the difficulty of blotting free surface liquid completely in the present study. However, it can be concluded that the deviation of observed flux value at the feed water weight fraction of 0.1 from the caluculated value is due to swelling. Permeselectivity towards water was not improved significantly by the hydroxyl modification of polysulfone in comparison with pervaporation results of the parent polysulfone membrane. ${ }^{24}$ This might be due to the membrane swelling by ethanol.

Using membranes from modified polysulfones with five kinds of hydroxyl groups, we investigated the effect of substituent environment surrounding the hydroxyl group on pervaporation phenomena. For this purpose, pervaporation data at the feed water weight fraction of 0.9 were used, because the swelling effect of ethanol on membrane performance was thought to be the least among investigated feed compositions. Figure 4 shows the relationship between the separation factor and the ratio of surface area of hydroxyl group ${ }^{27}$ to that of hydrophobic moiety ${ }^{27}$ surrounding the hydroxyl group for the feed water weight fraction of 0.9 . Obviously, hydrogen-bonding ability of the hydroxyl group plays an important role in the present pervaporation system. Hydrogen-bonding interaction is a kind of dipole-dipole interaction, which highly depends on both direction and distance. The higher the surface area ratio $\left(\mathrm{A}_{-\mathrm{OH}} / \mathrm{A}_{-\mathrm{R}}\right)$, the higher the probability that the hydroxyl group in the modified polysulfone and the water molecule are located in an optimum alignment to interact with each other. This can lead to an increase in hydrogen-bonding interaction. Consequently, an increase in permselectivity towards water results. Furthermore, an increase in surface area ratio allows an easier approach of the water molecule to the hydroxyl group introduced into the polysulfone membranes. This also leads to an improvement in permselectivity towards water. However, too strong hydrogen-bonding interactions will reduce the diffusivity of water in the membrane, resulting in a lower permselectivity towards water. These two antagonistic effects have resulted in a maximum in the separation factor 
shown in Figure 4. It can be concluded that an optimum environment, with a reasonable hydrophobic-hydrophilic balance, is necessary for selective permeation of water.

\section{CONCLUSION}

Modified Udel P-3500 membranes bearing various kinds of hydroxyl moieties showed permselectivity towards water in the separation of aqueous ethanol solutions by pervaporation. Swelling phenomena of modified membranes in the presence of ethanol prevented a significant improvement in membrane performance. According to the analysis of the permeation data by the solution-diffusion model, the diffusion coefficient for water was the exponential function of both water and ethanol concentrations, while that for ethanol was the exponential function of ethanol concentration alone. Calculation by using a set of transport equations and associated transport parameters reproduced the experimental data, including the weight fraction of water in the permeate and the total flux, very well when the water weight fraction in the feed was above 0.1 . However, the calculated and experimental data did not agree when the water weight fraction was 0.1 , probably due to the swelling by ethanol at the high feed ethanol content. Hydrogen-bonding between the hydroxyl group of the polymer and water appears to govern the membrane selectivity. As the intensity of hydrogen-bonding, represented by the surface area ratio $\left(A_{-\mathrm{OH}} / A_{-\mathrm{R}}\right)$, increases, the permselectivity of the membrane is expected to increase. On the other hand, too strong hydrogen-bonding interactions will reduce the diffusivity of water in the membrane, leading to a lower permselectivity. These two opposing effects resulted in a maximum of the separation factor as a function of the surface area ratio $\left(A_{-\mathrm{OH}} / A_{-\mathrm{R}}\right)$. It was apparent that pervaporation phenomena were highly dependent on the substituent environment surrounding hydroxyl group.
Acknowledgment. We are grateful to Dr. C. E. Capes, NRC, for his continuous encouragement and Mr. C. M. Tam for helpful discussions.

\section{APPENDIX}

\section{Nomenclature}

$B_{\mathrm{EE}}$, coefficient of the exponential model for ethanol $\left(\mathrm{mol}^{-1} \mathrm{~m}^{3}\right)$

$B_{\mathrm{WE}}$, coefficient of the exponential model for water $\left(\mathrm{mol}^{-1} \mathrm{~m}^{3}\right)$

$B_{\mathrm{Ww}}$, coefficient of the exponential model for water $\left(\mathrm{mol}^{-1} \mathrm{~m}^{3}\right)$

$C_{\mathrm{E}, 0}$, concentration of ethanol in the feed solution $\left(\mathrm{mol} \mathrm{m}^{-3}\right)$

$C_{\mathrm{w}, 0}$, concentration of water in the feed solution

$J$, total flux

$J_{\mathrm{E}}$, flux of ethanol $\left(\mathrm{molm}^{-2} \mathrm{~h}^{-1}\right)$

$J_{\mathrm{W}}$, flux of water $\quad\left(\mathrm{mol} \mathrm{m}^{-2} \mathrm{~h}^{-1}\right)$

$l$, thickness of the membrane (m)

$P_{0, \mathrm{E}}$, permeability coefficient of ethanol in the membrane $\left(=D_{0, \mathrm{E}} K_{\mathrm{E}}\right) \quad\left(\mathrm{m}^{2} \mathrm{~h}^{-1}\right)$

$P_{0, \mathrm{w}}$, permeability coefficient of water in the membrane $\left(=D_{0, \mathrm{w}} K_{\mathrm{w}}\right) \quad\left(\mathrm{m}^{2} \mathrm{~h}^{-1}\right)$

$\alpha$, separation factor

\section{REFERENCES}

1. M.D. Guiver, J.W. ApSimon, and O. Kutowy, J. Polym. Sci., Polym. Lett. Ed., 26, 123 (1988).

2. M.D. Guiver, O. Kutowy, W.A. McCurdy, and J.W. ApSimon, Proceedings of International Membrane Conference on the 25th Anniversary of Membrane Research in Canada, M. Malaiyandi, O. Kutowy, and F. Talbot, Ed., National Research Council, Ottawa, 1986, p 187. NRCC No. 27422.

3. M.D. Guiver, J.W. ApSimon, and O. Kutowy, U.S. Patent 4797457 (Jan. 10, 1989) and U.S. Patent 4 833219 (May 23, 1989).

4. M.D. Guiver, A.Y. Tremblay, and C.M. Tam, in "Advances in Reverse Osmosis and Ultrafiltration," T. Matsuura and S. Sourirajan, Ed., National Research Council, Ottawa, 1989, p 53. NRCC No. 29895.

5. M.D. Guiver, O. Kutowy, and J.W. ApSimon, Polymer, 30, 1137 (1989).

6. M.D. Guiver, S. Croteau, J.D. Hazlett, and O. 
Kutowy, Br. Polym. J., 23, 29 (1990).

7. A. Noshay and L.M. Robeson, J. Appl. Polym. Sci., 20, 1885 (1976).

8. B.C. Johnson, I. Yilgör, C. Tran, M. Iqbal, J.P. Wightman, D.R. Lloyd, and J.E. McGrath, J. Polym. Sci., Polym. Chem. Ed., 22, 721 (1984).

9. W.H. Daly, Macromol. Sci.-Chem., A22, 713 (1985).

10. W.H. Daly, S. Lee, and C. Rungaroonthaikul, in "Chemical Reactions on Polymers," J.L. Benham and J.F. Kinstle, Ed., ACS Symp. Ser. 364, American Chemical Society, Washington, D.C., 1988, p 4.

11. A. Higuchi, N. Iwata, M. Tsubaki, and T. Nakagawa, J. Appl. Polym. Sci., 36, 1753 (1988).

12. Y. Nagase, A. Naruse, and K. Matsui, Polymer, 30, 1931 (1989).

13. Y. Nagase, A. Naruse, and K. Matsui, Polymer, 31, 121 (1990).

14. A. Higuchi, N. Iwata, and T. Nakagawa, J. Appl. Polym. Sci., 40, 709 (1990).

15. A. Higuchi and T. Nakagawa, J. Appl. Polym. Sci., 41, 1973 (1990).

16. A. Warshawsky, N. Kahana, A. Deshe, H. E. Gottlieb, and R.J. Arad-Yellin, J. Polym. Sci., Polym. Chem., 28, 2885 (1990).

17. A. Warshawsky and O. Kedem, J. Membrane Sci.,
53, 37 (1990).

18. J.M. Mohr, D.R. Paul, I. Pinnau, and W.J. Koros, J. Membrane Sci., 56, 77 (1991).

19. A. Higuchi, S. Mishima, and T. Nakagawa, $J$. Membrane Sci., 57, 175 (1991).

20. M. Yoshikawa, T. Ohsawa, M. Tanigaki, and W. Eguchi, J. Appl. Polym. Sci., 37, 299 (1989).

21. M. Yoshikawa, T. Yukoshi, K. Sanui, and N. Ogata, J. Polym. Sci., Polym. Chem. Ed., 24, 1585 (1986).

22. M. Yoshikawa, Y. Adachi, H. Yokoi, K. Sanui, and N. Ogata, Macromolecules, 19, 47 (1986).

23. M. Yoshikawa, T. Yukoshi, K. Sanui, and N. Ogata, J. Appl. Polym. Sci., 33, 2369 (1987).

24. M. Yoshikawa, H. Hara, M. Tanigaki, M. Guiver, and T. Matsuura, Polymer, in press.

25. M.D. Guiver and W.W.Y. Lau, Proceedings, IUPAC International Symposium on Speciality Polymers, Singapore, $1990, \mathrm{p} 94$.

26. J.A. Riddick and W.B. Bunger, "Organic Solvents," 3rd ed, Wiley, New York, 1970.

27. A. Bondi, "Physical Properties of Molecular Crystals, Liquids, and Glasses,” Wiley, New York, 1968.

Issued as NRCC No. 34220 